\title{
Effect of Panel Zone Strength on Ductility Capacity of Welded Beam-to- column Connections without Continuity Plates
}

\author{
${ }^{\mathrm{a} Y}$.CHEN, ${ }^{\mathrm{b}} \mathrm{M} . \mathrm{LEI}$ \\ ${ }^{a}$ Department of Building Engineering, Tongji University, Shanghai, China \\ ${ }^{b}$ Suzhou Institute of Industrial Technology, Suzhou,China,School of Civil Engineering, Southwest \\ Jiaotong University, Chengdu ,China
}

KEYWORD: panel zone; web doubler plate; beam -to-column connection; ductility; continuity plates

ABSTRACT: Panel zone strength in welded moment-resisting-frame connections have a significant effect on the stress and strain distribution in the connection and consequently on connection performance. It is generally believed that panel zone yielding is a yield mechanism that contributes to ductility of moment frame connections, but connections with excessive panel zone deformation may have premature connection fracture and reduced ductility. The conclusion was drawn based on the theoretic analysis and tests on T-shaped connections with continuity plates. effect of panel zone strength on ductility capacity of welded beam-to-column connections without continuity plates were investigated through three-dimensional, nonlinear, finite-element analyses of connection subassemblies. results show that strong panel zone contributes to ductile performance of connections without continuity plates. The ductility of welded beam-to-column connection can be significantly improved by removing the continuity plates and providing with strong panel zone. The conclusion drawn from this paper is verified by experimental data available in the literature.

\section{INTRODUCTION}

The 1994 Northridge Earthquake and the 1995 Kobe Earthquake caused severe damage of welded beam-to-column connections by brittle fracture. Damage reports following the Northridge earthquake indicated that most fractures occurred in the weld mental of bottom flange or in the base mental near the toe of weld access hole. It is generally believed that low fracture toughness of the weld mental is the primary cause which accounts for brittle failure of the moment connections. To determine the causes of the damage and to provide solutions to the problems, a great amount of research work has been carried out to address the issues regarding the unexpected brittle failure of welded beam-column connections. The results of cyclic loading tests on 14 full-scale beam-column connections specimen conducted by Nakashima indicated that dynamic loading had no detrimental effect on ductility, and that modified details of the weld access hole had an effect of preventing cracks initiating from the toe of the weld access hole ${ }^{[1]}$. Tests on unreinforced steel moment connections run by Stojadinovic shown that all specimens achieved a mean plastic rotation of $1.5 \%$ radian which was not sufficient to satisfy the plastic rotation requirements for steel moment-resisting frames in regions of high seismicity ${ }^{[2]}$. Ricles focused on FE analysis and found that different weld access holes and panel zone strength had significant effect on the ductility of welded moment connections ${ }^{[3]}$. Roeder generalized all the factors which influenced connection performance ${ }^{[4]}$.

Although numerous experimental investigations and theoretical analyses have been performed to investigate all possible causes associated with brittle failure of the welded beam-column connections, there still exist some problems which cannot be fully recognized. Panel zone in welded momentresisting-frame connections have a significant effect on the stress and strain distribution in the beam flange weld and consequently on connection performance. In an effort to investigate the effects of panel zone strength on ductility of exterior connection without continuity plates, nonlinear analysis of welded beam-column connections with different panel zone strength under cyclic loading was performed. 


\section{VERIFICATION OF FE ANALYSIS}

The finite element model has been verified by comparing the measured cyclic response of the connection specimen T1 (Ricles,2002) with the predicted response. The test setup for the Specimens T1 is shown in Fig. 1. The connection subassembly is T-shaped and consists of W36 $\times 150$ beam connected to W14 $\times 311$ column. The beam flanges is joined to the column flange with field groove welds. The beam web is connected to column flange using a groove weld with supplemental fillet weld around all edges of the shear tab. Continuity plates are located at the both sides of column. The beam is modeled as a cantilever beam and the column ends are simple supported. The analysis model shown in Fig. 2 is used for parametric analysis which is the same as that used in the experimental study by Ricles(2002). The top of the column is loaded cyclically with increasing displacement amplitudes and the loading history is shown in Fig.3. Different connection configurations are created by changing some details of the specimen T1.

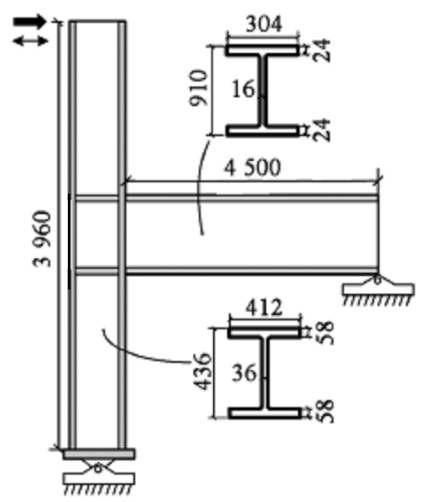

Fig.1. Test setup for Specimen T1

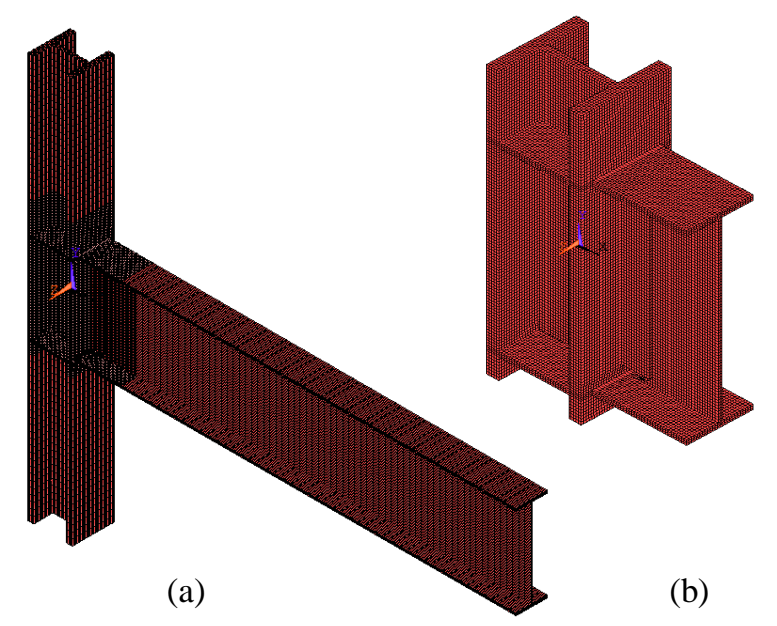

Fig.2 Finite element model of the specimen T1

(a) global model (b) sub-model

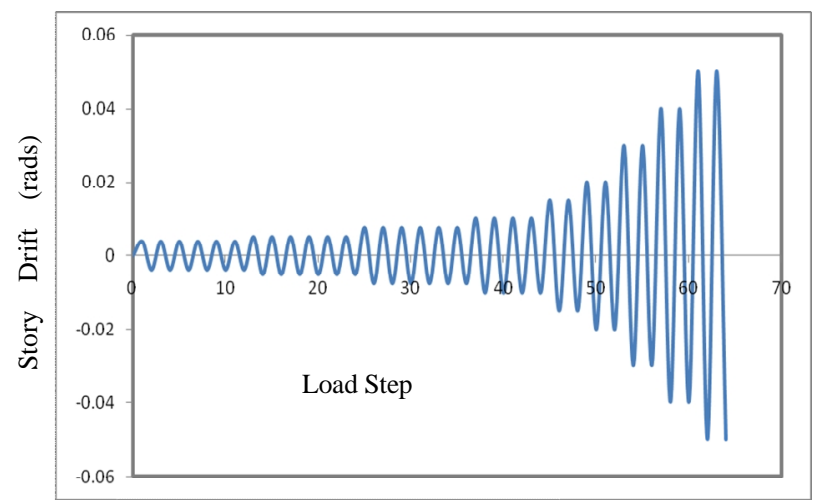

Fig.3. Loading History 
The 3D FEMS of the connection subassemblies have been developed for the parametric study using the general-purpose nonlinear finite-element analysis program ANSYS. An eight-node brick element referred as SOLID185 is used. The models include details such as all welds and weld access holes. Geometric and material nonlinearity are included in the analysis, where measured material properties are used. The Young's modulus and the Poisson's ratio of the base mental are 200GPa and 0.3, respectively. The tested yielding stress of the specimen are listed in Table 1. A bilinear stress-strain relation is used, with the tangent modulus equal to $2.8 \mathrm{GPa}$ for both base mental and weld mental. Geometric nonlinearities are accounted for through a small-strain, large-displacement formulation. The FEM analytical results are compared with the test result in Fig.4, which shows that the experimental and analytical behaviors agree well. The FEM program code has sufficient precision to compute the cyclic behaviors of the welded beam-column connections accurately.

Table 1 Material properties of the test Specimen T1

Material Yielding stress ( $\mathrm{MPa})$

Tensile stress ( $\mathrm{MPa})$

Beam flange/web $\quad 380 / 426$

$494 / 518$

Column flange/web $\quad 326 / 339$

$480 / 483$

Continuity plate

Shear tab

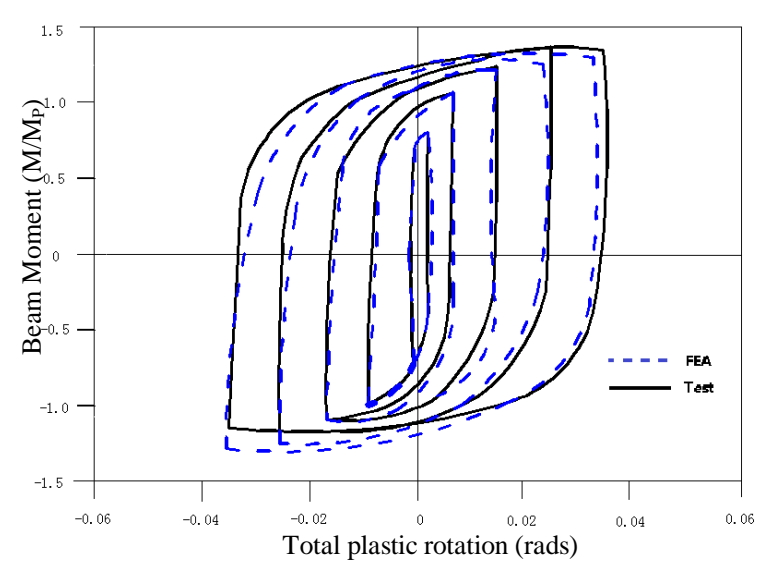

Fig.4 Comparison between measured and computed beam moment versus total plastic rotation response

\section{FE ANALYSIS}

El-Tawil evaluated the effects of the panel zone strength on ductile behavior of the exterior connections with continuity plates using finite element models of a number of welded beam- to-column connections. Comparisons of the analysis results show that although the panel zone can effectively contribute to overall connection ductility, a weak panel zone can also lead to greater potential for 
brittle fracture at higher connection plastic rotations. Recently, Rahiminia carried out extensive experimental studies to find a deep understanding in the effects of panel zone deformation on inelastic behavior of the connections. It is shown that cumulative plastic rotation capacity of beam component is almost constant regardless of the amount of panel shear deformation and frame total plastic rotation capacity is increased by reduction of panel zone strength.

However, the effects of panel zone strength on ductility capacities of the exterior connections without continuity plates may be totally different because thicker column web can effectively reduce maximum stress and plastic strain at the center of beam flange weld.

To study the effects of panel zone strength on the behavior of welded exterior connections without continuity plates, the finite element model of Specimen T1 was used. For comparison, continuity plates in the Specimen T1 were removed, and the model was named T0. Finite element model T0(weakest panel zone) was used to investigate the effects of panel zone strength on ductile behavior of the exterior connections not having continuity plates. The other configurations were created by changing the column web thickness in order to change the panel zone strength. Specimen T5(mild panel zone) was similar to Specimen T0 except that it had a 13-mm doubler plate in the column panel zone. Specimen T5D(strongest panel zone) was provided with two 13-mm doubler plates at both sides of column web and had the strongest panel zone. Fig.5 shows the distribution of the accumulated plastic strain across the beam flange width at the story drift 5\% radians. Obviously, the maximum accumulated plastic strain at the center of beam flange decreases significantly with the increase of panel zone strength. The ductility capacities of the exterior connections can be pronounced improved by removing the continuity plates and providing with strong panel zone.

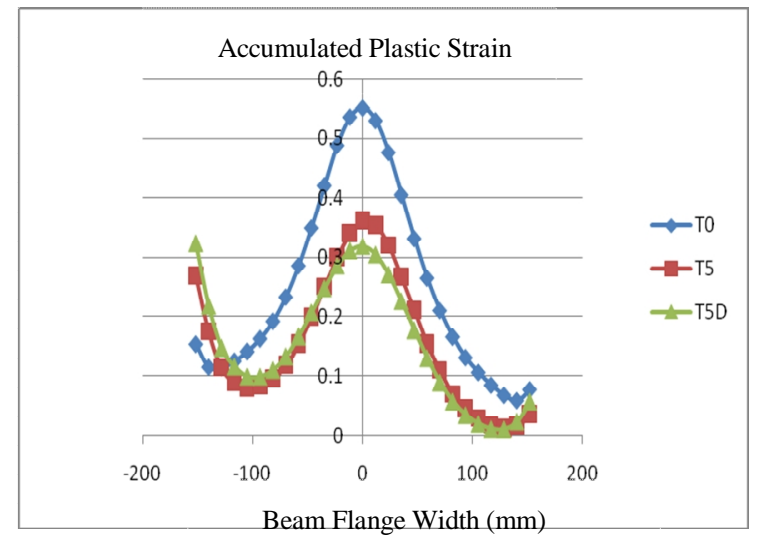

Fig.5 Distribution of accumulated plastic strain across beam flange width

\section{EXPERIMENTAL VALIDATION}

The results from the analytical study have been verified in an experimental study performed by Ricles et al.(2000). The experiment involved the inelastic cyclic test of 6 full-scale T-shaped exterior connection specimens and 5 full-scale interior connection specimens. Specimens T1-T6 were all exterior connection specimens with the same column and beam size, Specimens C1-C5 were cruciform connection specimens. Each specimen was subjected to a history of cyclic loading following the loading protocol established by SAC. Specimen T1-T4 were provided with continuity plates and no double plates, specimens T5 and T6 were provided with doubler plates and no continuity plates. A description of the connection detail of each of the specimens is given in Table 2. The specimen details and inelastic behavior were described in detail by Ricles(2000). The total plastic drift angle achieved by each exterior specimen was summarized in Table 3. As is shown in Table 4, the exterior connection specimens without continuity plates and with strong panel zone show satisfactory ductility while specimens with continuity show little ductility, which is in good agreement with the analytical results. 
Table 2 Test Specimen Matrix for exterior connections

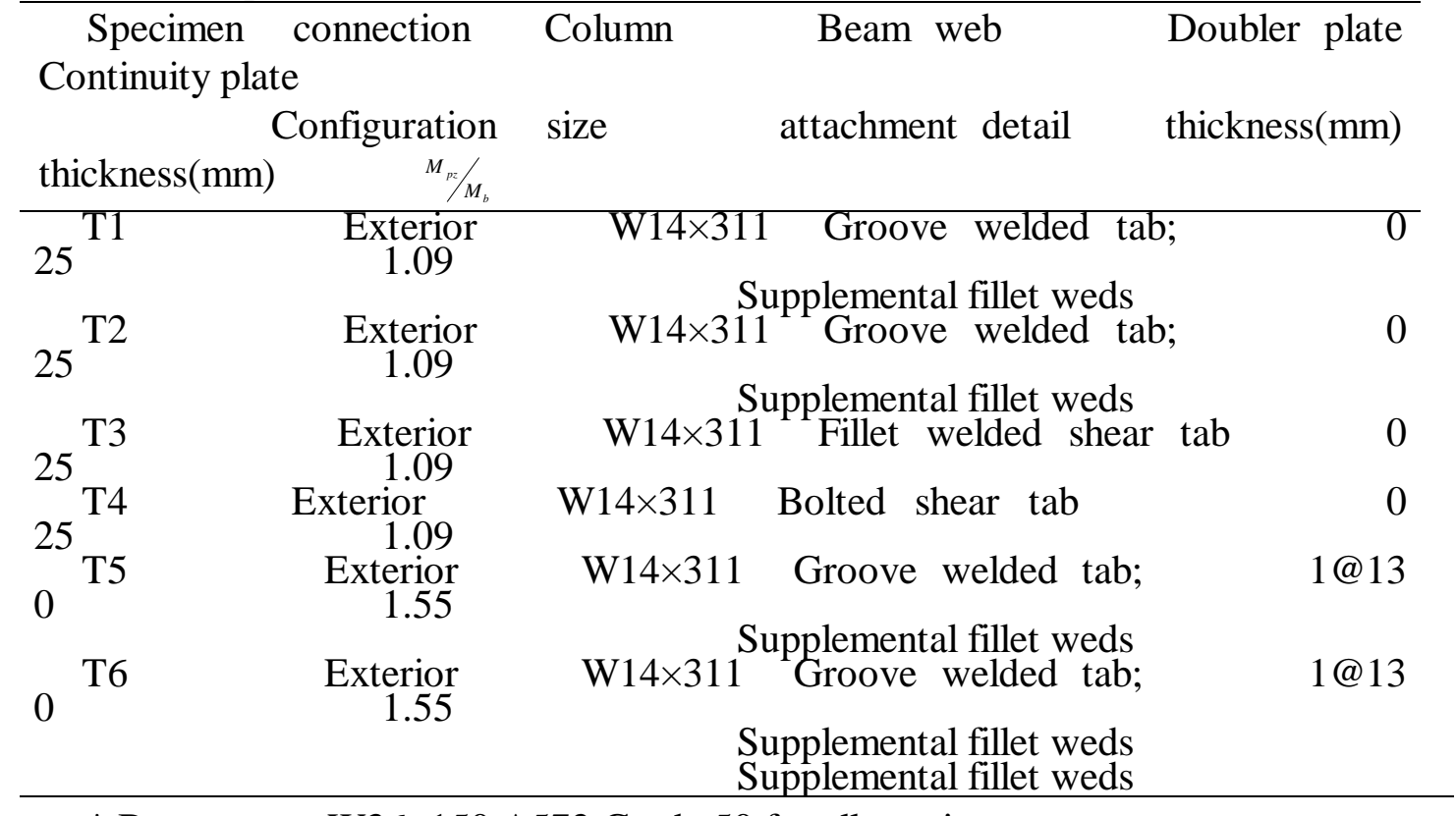

* Beams were W36×150,A572 Grade 50 for all specimens

Table 3 Summary of Exterior Connection Specimen performance

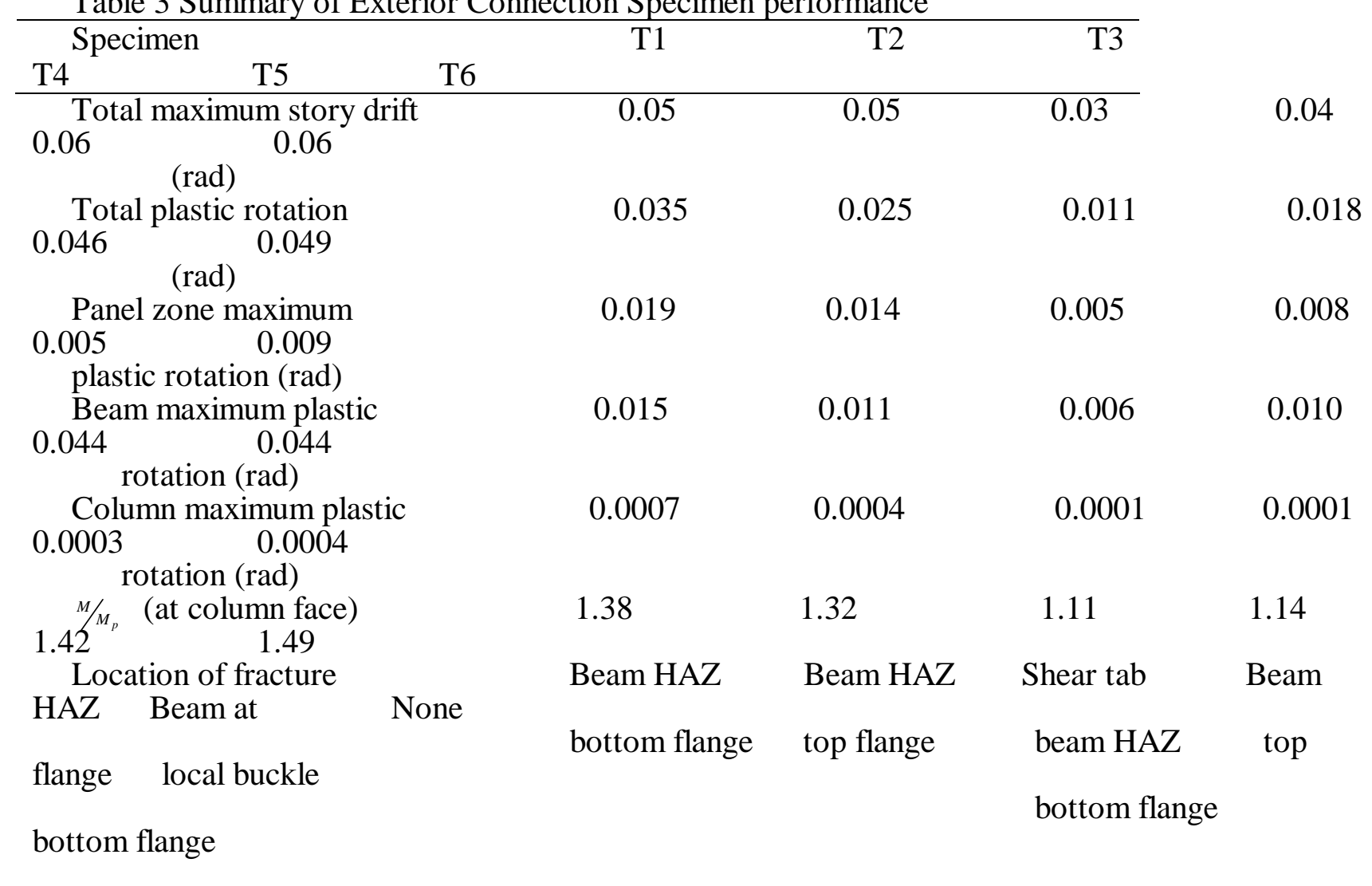

* HAZ denotes heat affected zone

\section{CONCLUSIONS}

To investigate effects of panel zone strength on cyclic behavior of welded beam-to-column connections without continuity plates, nonlinear analyses of the connections were carried out. The analytical results are in good agreement with the test results performed by Ricles. Satisfactory ductility of the 
welded beam-to column connection

without continuity plates can be achieved if the connections are designed with strong panel zone.

\section{REFERENCES}

[1] Masayoshi Nakashima, Keiichiro Suita, Kiyotaka Morisako.1998. Test of welded beam-column subassemblies. I:Global behavior. Journal of Structural Engineering,124(11):1236-1244.

[2]Keiichiro Suita, Masayoshi Nakashima, Kiyotaka Morisako. 1998. Test of welded beam-column subassemblies. II :Global behavior. Journal of Structural Engineering, 124(11):1244-1252.

[3]Stojadinovic B. Goel S.C., Lee K., et al. 2000. Parametric tests on steel moment connections. Journal of Structural Engineering, 126(1):40-49.

[4]Ricles J.M., Fisher J.W., Lu L.W.. 2002. Development of improved welded moment connections for earthquake-resistant design. Journal of Constructional Steel Research, 58:565-604.

[5]Changshi Mao, James Ricles, LE-Wu,Lu, et al. 2001. Effect of Local Details on Ductility of Welded Moment Connections, Journal of Structural Engineering, 127(9):1036-1044.

[6]Roeder. 2002. General issues influencing connection performance. Journal of Structural Engineering. 128(4):420-428

[6]Sherif El-Tawil, Egill Vidarsson, Tameka Mikesell, et al. 1999. Inelastic behavior and design of steel panel zones. Journal of Structural Engineering, 125(2):183-193

[7] Sherif El-Tawil, Tameka Mikesell, Sashi K. Kunnath. 1999. Effect of local details and yield ratio on behavior of FR steel connections. Journal of Structural Engineering, 126(1):79-87

[8]Dexter, R.J., Hajjar,J.F., Cotton, S.C.,et al. 1999. Reassessment of design criteria and new alternatives for column transverse stiffeners(continuity plates) and web doubler plates: interim report, Structural Engineering Report ST-99-3, Dept. of Civil Engineering, U. of Minnesota, Minneapolis, Minnesota

[9]Faramarz Rahiminia. ,2013. Effects of joints panel shear deformation on elasto-plastic behavior of steel beam-to-column connections. Doctoral thesis submitted to Kobe University, Kobe University.

[10]Amon Wongkaew. 2002. Development of improved details for unreinforced welded steel moment connections. Ph.D. Thesis submitted to University of Michigan.

[11]FEMA. 2000. State of the Art Report on connection performance. Report No. FEMA 355D, FEMA, Washington, DC.

[12]AISC. 2002. Seismic provisions for structural steel buildings. AISC,Chicago,IL. 